\title{
Multi-Disciplinary System Design Optimization of a Launch Vehicle Upper-Stage
}

\author{
Mostafa Zakeri ${ }^{1}$, Mehran Nosratollahi ${ }^{1}$, Alireza Novinzade²
}

\begin{abstract}
The design method presented in this paper is related to the upper-stage system and its instrumentation, expedition and facilitation so as to transfer the satellite from the destination orbit to the target orbit. We used an integrated design method with a structure based on multidisciplinary system design optimization and developed a simple systematic interference method for designing aerospace products. The subsystems' convergence in an optimized environment, matrix relationship, and integration of the subsystems' parameters and presentation of design give results while meeting all requirements and considering the limitations of the design were the main aims of the research. Instead of a merely mathematical optimization design, in the present study a new design method with a systematic multipurpose optimization approach was designed. In this context, the optimization means the parameters are optimized as a result of the design convergence coefficients. Validation of the design method was not only obtained through comparison with a specific product but also with the systematic parameters of all upper-stage systems with a similar operation through the results of statistical design graphs. The approximate similarities of the results indicate an acceptable and genuine design with a quite systematic approach which is better than an unreal and merely optimized design.
\end{abstract}

KEYWORDS: Upper stage, Systems design, Multidisciplinary design optimization, Systems integration.

\section{INTRODUCTION}

In a article named "Technologies for future precision strike missile systems - missile design technology" (Fleeman 2001), there is a survey of missile technology concepts, influential parameters in design, and balance among subsystems, using new technologies with lower weight and cost communicating with the launcher. Overall configuration as well as missile simulation results from such a design method. The detailed explanations for the study are available in his book of Tactical Missiles Design. It needs to be mentioned that design depth is limited in the method yet the functional area is high while lack of integration and systemic communications implementation are the biggest weak points in this method which he explains and completes in his 2012 edition of the book. It is claimed in the study that all main parameters of a missile at conceptual design are taken into consideration while the missile has operational capability. Operational capability as well as systemic relation integration is the first act in the current study.

The history of transition from classic design to modern design is not accountable in this study, however, some developed countries have been able to take advantage of system design and multidisciplinary optimization methods to improve conceptual design process through considerable savings in design time and costs (Olds 1993).

Brown and Olds (2006) surveyed multi-objective optimization techniques of collaborative optimization (CO), modified collaborative optimization (MCO), bi-level integrated system synthesis (BLISS), and all at once (AAO) on a reusable satellite. The study claims that the best design method cannot be chosen since such activities are for research

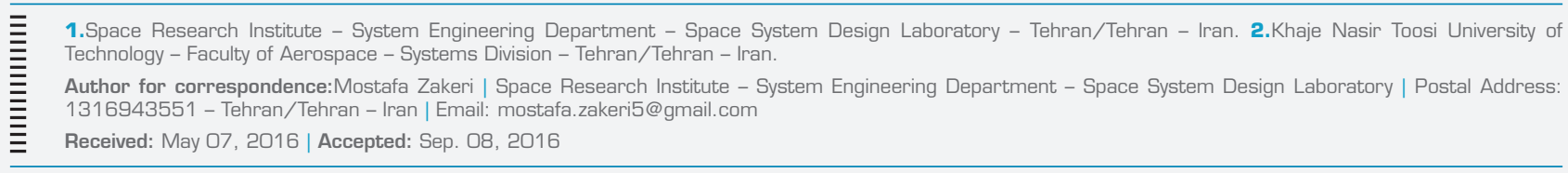


purposes only and require various studies on the results. Systemic design activities are briefly mentioned in this study while most of the activities are focused on comparing 3 design techniques. In the final conclusion, a comparison is made among design methods based on running time as well as quality comparisons, which could be said that BLISS designed outputs have higher quality.

Balesdent et al. (2011) surveyed various multipurpose optimization methods in space systems design quantitatively. Various MDO methods to design satellite missiles are surveyed in the study and some features, such as strength, price calculations, flexibility and convergence speed and problem implementation are taken into consideration so as to select the most suitable design method in designing launch vehicle. Mathematical equations of optimization of every method as well as main profile of the algorithm with optimization activities of every method are mentioned briefly. Selection of the optimal method to design space system based on the mission and various situations such as implementation time, cost, complexity, etc. is the final conclusion of the study (Balesdent et al. 2011).

Riddle (1998) states that using MDO in designing complex systems comes with 2 obstacles. One of them originates from disconnected and nonlinear essence of design process most of mathematical optimization methods are facing. One other unattractive point of MDO methods is design teams' unwillingness to use it and similarity of automatic decisionmaking with creative process of innovative design.

Tsuchiya and Mori (2002) claimed that in spite of the higher speed of MDO with parametric methods, and based on which studies are reported to improve system and destination optimization for reusable launch vehicles (RLV), they are still recognized unsuitable for space systems design, especially satellite-carrying missiles which are essentially more complicated in configuration steps and trajectory design.

The need to design with a systematic approach in addition to design implementation based on physics of an aerospace product attracts some researchers to optimized systematic design. Aldheeb et al. (2012) tried to create an optimized design for a Micro Air Launch Vehicle.

In the present study, optimization and trajectory design are done through a design algorithm with systematic approach to reduce payload mass. The look on functional design physics in the main algorithm of the article and model of subsystems is clear. Villanueva et al. (2013) used a systematic approach in an article to design solid fuel engine.
Conceptual design in the current study is optimized through a genetic algorithm.

It could be claimed that creation of a systematic approach and transforming MDO to multi-disciplinary system design optimization (MSDO) includes development of MDO methods which develops operational capability based on MDO. MSDO approach is available in a limited number of the articles.

According to Wronski and Gray (2004), one can verify a comprehensive MSDO implementation in a specific case in the Massachusetts Institute of Technology (MIT). The specific importance of the study is that it gives a true expression of MSDO systematic design, multipurpose optimization and an obvious process of the algorithm.

Additionally, design and multipurpose optimization of an aircraft was studied through implementation and integrated design tools so as to predict and optimize the implementation and related expenditures of commercial aircrafts design and production with the aim of reducing the noise through accurate selection of configuration and mission parameters (Diedrich et al. 2006). After surveying some design samples, a brief look to upper stage activities are made.

Engine and trajectory design in Casalino and Pastrone (2010) is optimized simultaneously. Systematic design is brief in the study and it could be included among the optimization articles with systematic approach for propulsion engine.

An upper stage activity is presented with a brief look at upper stage engine of solid fuel engine (Casalino and Pastrone 2010). Adami et al. (2015) designed an upper stage performed through three forms of MDO. Mathematically, a detailed comparison among the three design methods is presented. The optimal proof of choice is surveyed mathematically.

After considering the aforementioned articles in addition to their quantitative and qualitative analyses, Table 1 presents a summary of their features.

\section{METHODOLOGY}

Designing an optimized multidisciplinary system is a modern example of aerospace product design. MSDO can be complex product design process and multidisciplinary engineering systems. In this method, the subsystems are related to each other and to a system in an optimized and converging space. Also the main feature of this method is the 
Table 1. Distribution of mass components.

\begin{tabular}{|c|c|c|c|c|c|c|c|}
\hline $\begin{array}{l}\text { Design } \\
\text { methods }\end{array}$ & $\begin{array}{l}\text { Physics-based } \\
\text { methods }\end{array}$ & $\begin{array}{c}\text { Mathematical-based } \\
\text { methods }\end{array}$ & $\begin{array}{c}\text { Full } \\
\text { configuration }\end{array}$ & $\begin{array}{l}\text { Balanced } \\
\text { subsystems } \\
\text { [converge] }\end{array}$ & $\begin{array}{c}\text { Requirement } \\
\text { meeting between } \\
\text { subsystems }\end{array}$ & $\begin{array}{c}\text { Subsystems } \\
\text { design } \\
\text { depth }\end{array}$ & $\begin{array}{l}\text { Imbedded } \\
\text { baseline } \\
\text { statistics data }\end{array}$ \\
\hline $\begin{array}{l}\text { System design } \\
\text { optimization }\end{array}$ & $\times$ & $\times$ & - & $\times$ & - & $\times$ & $x$ \\
\hline MDO & - & $x$ & $x$ & - & $x$ & - & $x$ \\
\hline $\begin{array}{c}\text { MSDO } \\
\text { [this study] }\end{array}$ & $\times$ & $\times$ & $\times$ & $\times$ & $\times$ & $\times$ & $x$ \\
\hline
\end{tabular}

presence of human expert in the Designing tool environment and integration of all designing subdivisions. The aim of this approach is the creation of sophisticated and advanced engineering systems that are competitive not only in terms of performance but also in terms of value of life cycle.

The most important properties of MSDO method can be stated as follows:

- Deal with design models of realistic size and fidelity that will not lead to erroneous conclusions.

- $\quad$ Reduce the tedium of coupling variables and results from disciplinary models.

- Allow for creativity while leveraging rigorous, quantitative tools in the design process. Hand-shaking: qualitative versus quantitative.

- Data visualization in multiple dimensions.

- Incorporation of higher-level upstream and downstream system architecture aspects in early design: staged deployment, safety and security, environmental sustainability, platform design, etc.

In this procedure, design algorithm similar to other design algorithms is not of tree type or merely a mathematical optimization. The MSDO algorithm is designed to link all the subdivisions directly to each other and the best convergence is applied according to physics and subdivisions. In this way, the designer can easily put all the limitations and restrictions of design to work. In this paper, the concepts of design and multistep optimization are used in a strategic computing environment to design upper-stage which transfers from parking orbit to the target orbit. Presented parameters in this procedure are classified as:

- Design or independent variables: including fuel mass ratio, engine structural mass ratio to the whole engine, etc.

- $\quad$ Simple limitations: including mass ratios, $\mathrm{I}_{\mathrm{sp}}$, etc.
- Restrictions: diameter, orbital altitude, payload.

- Combined merit functions: aiming at minimizing the total mass and designing the best way of sending the satellite to the target orbit.

The most important specifications of the MSDO algorithm are as follows:

- Offering new approaches in systematic design derived from MSDO designing method.

- Using statistical processing in the design process (increasing accuracy and rapid convergence).

- Offering innovative convergence methods.

- Optimizing system and subsystems' design parameters by using communication matrixes.

- Convergence of designing upper stage with previous stages of the rocket.

- Integrating all the design parameters and meeting all the restrictions and requirements.

- Ability to enter any new special requirement in the way of designing.

Algorithm design of upper stage includes the following:

- Statistical designing and analysing statistical data.

- Designing the layout of subsystems and subdivisions.

- Dynamics and trajectory design.

- Propulsion system design and tank design.

- Feeding system design.

- Analysis of mass-dimensions and mass associated with the previous stage of launch vehicle design.

- Structural design and stiffener.

- Systematic analysis (configuration, integrating and optimization).

All the requirements and limitations of designing the upper stage is done based on the objectives, bottlenecks, and administrative constraints. These constraints are applied in all the phases with the presence of the designer in the design 
environment. All the requirements and restrictions can be classified as follows:

- The requirements of trajectory.

- The requirements of the launch vehicle and launch.

- The requirements of subsystems and subdivisions.

- The requirements of construction and assembly.

- The limitations in choosing the hardware.

Basic hypotheses regarding the design of upper stage are as follows:

- Payload.

- Parking orbit and target.

- Mechanical properties.

- Helium mechanical properties.

- The characteristics of the chosen fuel.

- Safety factors.

- Temperature of tanks and the flame.

The main body of the communication among subsystems, within each other, and the system is created according to the design matrix. Design matrixes are the designer's guide for displaying design communications and the effects of the parameters on each other (Peoples and Schuman 2003). The communicative matrix between the components of propulsion system is shown in Fig. 1 due to the importance of the communication of the propulsion system components. The most important design matrix is the comprehensive design matrix which is shown in Fig. 2. Only the main parameters of design are mentioned in the matrixes.

In designing the MSDO algorithm, several optimization and convergences were used. The goal of optimization is to achieve the least amount of goal parameters; however, the goal of convergence is to converge all design parameters within each other as well as meeting all the requirements and limitations. Optimization includes:

- Optimizing comprehensive design matrix based on the MSDO and through genetic algorithm.

- Optimizing trajectory through genetic algorithm.

- Optimizing propulsion system through genetic algorithm.

- Optimizing total mass through genetic algorithm.

- Optimizing the thickness of the crust and stiffener based on the buckling test and through genetic algorithm.

In Table 2, one can see the above-mentioned optimization properties. Design convergence items in MSDO algorithm include the acceleration of design process according to the statistical equations (reducing the time while increasing accuracy).

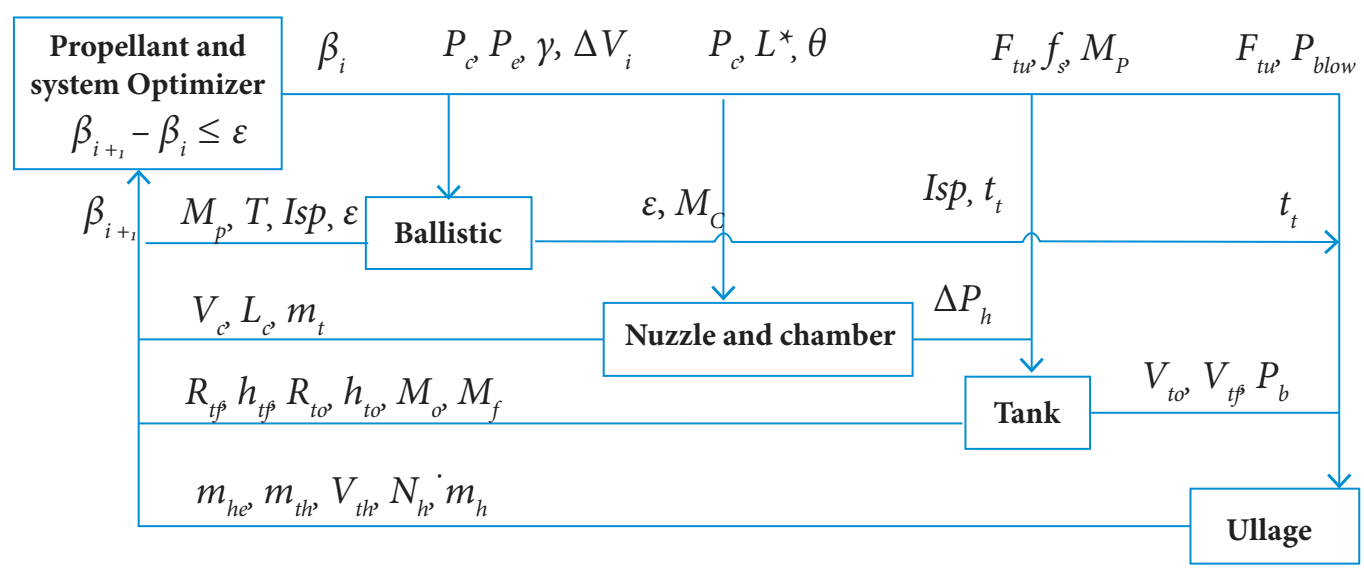

$P_{c}$ and $P_{e}$ : Chamber and exit pressure; $P_{\text {blow }}$ : Blow tanks pressure; $P_{h}$ : Distribution of the pressure gradient; $L^{*}$ : Combustion characteristic length; $\Delta V_{i}$ : Energy change in each burn $t_{t}$ :

Burn time distribution; $R_{t}$ and ht : Radius and height of the tank;

$V_{t h}$ and $m_{t h}$ : Volume and mass of the helium tanks'

$m_{h}$ : Blow rate; Nh: Number of blowing tanks; Vto, Vtf and Vc: Fuel tank capacity oxidation and combustion;

$\varepsilon$ : Expansion ratio; $T$ and $I s p$ : Thrust and specific impulse; $L_{c}$ : Combustion chamber length;

$F_{t u}$ : Yield stress; $f_{s}$ : Reliability factor; $t$ : Thickness of body structures; $t_{s m}:$ Maximum thickness of body structures.

Figure 1. Propulsion system matrix. 


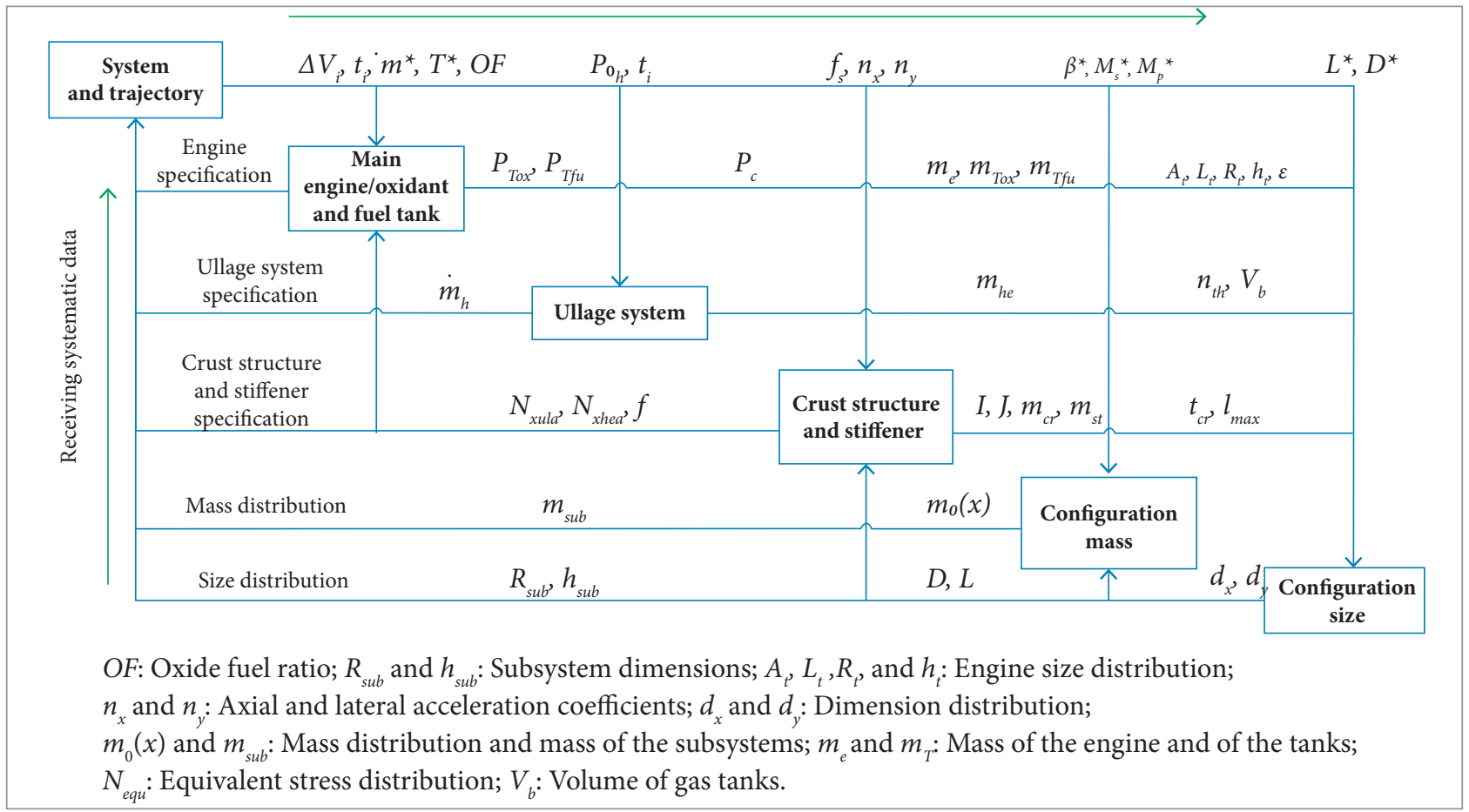

Figure 2. Design correlations matrix.

Primary values for design are obtained with statistical equations. Propulsion system convergence through propulsion system mass factor is defined as (Motlagh et al. 2013):

$$
\begin{aligned}
& \beta=M_{s} /\left(M_{s}+M_{p}\right) \\
& \beta_{\mathrm{n}}=\beta_{\mathrm{n}-1}<\varepsilon
\end{aligned}
$$

The convergence of upper stage compared with the previous stage launch vehicle is:

$$
\begin{aligned}
& \alpha=M_{p 1} / M_{p 2} \\
& \alpha_{\mathrm{n}}-\alpha_{\mathrm{n}-1}<\varepsilon
\end{aligned}
$$

In Fig. 3, it is presented the interference between convergence

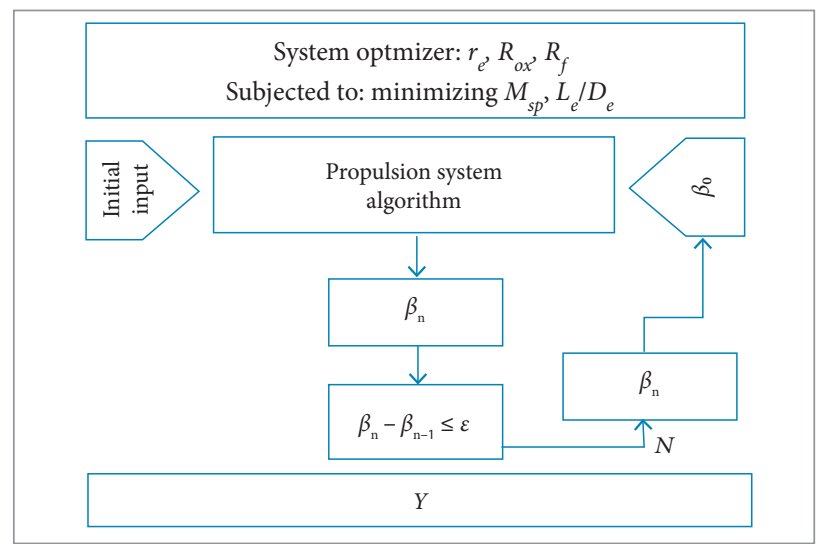

Figure 3. Interference between convergence and optimization.

Table 2. Optimization properties.

\begin{tabular}{|c|c|c|c|c|c|}
\hline System optimizer & Subjected to & Generations & Population & Crossover & Mutation \\
\hline MSDO optimization & Min: $M_{t}$ and $L / D$ & 100 & 100 & Scattered & Uniform $(0.2)$ \\
\hline Orbital optimization & Min: $M_{p}$ & 100 & 20 & Scattered & Uniform $(0.2)$ \\
\hline Propulsion optimization & Min: $M_{s p}$ and $L_{e} / D_{e}$ & 100 & 100 & Scattered & Uniform $(0.2)$ \\
\hline Total mass optimization & Min: $M_{t}$ & 100 & 20 & Scattered & Uniform $(0.2)$ \\
\hline Structure optimization & Min: $M_{s t}$ & 100 & 20 & Scattered & Uniform $(0.2)$ \\
\hline
\end{tabular}


and optimization of the algorithm (Fig. 4). Design variables are described in Table 3.

Design output includes the following:
- Systematic parameters of upper stage.

- Subdivisions' mass-dimension distribution.

- Systematic data of subdivisions.

Table 3. Design variables.

\begin{tabular}{|c|c|c|c|c|c|c|}
\hline System optimizer & Subjected to & $\begin{array}{l}\text { Design } \\
\text { variables }\end{array}$ & Name & Unit & Limitation & Description \\
\hline \multirow{4}{*}{ MSDO Optimization } & \multirow{4}{*}{$\begin{array}{c}\text { Min: } M_{t} \\
\quad \text { and } \\
L / D\end{array}$} & $P_{c}$ & Chamber pressure & bar & $5<\mathrm{P}_{\mathrm{S}}<15$ & - \\
\hline & & $O F$ & Oxide to fuel ratio & - & $3.5<\mathrm{OF}<4.5$ & \multirow{2}{*}{ According to fuel } \\
\hline & & $N_{h}$ & Number of helium tanks & - & $2<N_{h}<12$ & \\
\hline & & $N$ & Thrust to weight ratio & - & $1.5<\mathrm{n}<4.5$ & According to configuration \\
\hline \multirow{2}{*}{ Orbital Optimization } & \multirow{2}{*}{ Min: $M_{s p}$} & $r_{p t}$ & Transfer orbit Perigee & \multirow{2}{*}{$\mathrm{km}$} & \multirow{2}{*}{$200 \ldots 36000$} & \multirow{2}{*}{ According to orbit design } \\
\hline & & $r_{\alpha t}$ & Transfer orbit Apogee & & & \\
\hline \multirow{3}{*}{$\begin{array}{l}\text { Propulsion } \\
\text { Optimization }\end{array}$} & \multirow{3}{*}{$\begin{array}{l}\text { Min: } M_{s p} \\
\text { and } L_{e} / D_{e}\end{array}$} & $r_{e}$ & Nozzle exit & \multirow{3}{*}{$\mathrm{m}$} & $r_{e}<D$ & \multirow{3}{*}{-} \\
\hline & & $R_{o x}$ & Oxidizer tank profile & & $R_{o x}<D-t_{s}$ & \\
\hline & & $R_{f}$ & Fuel tank profile & & $R_{f}<D-t_{s}$ & \\
\hline $\begin{array}{c}\text { Total mass } \\
\text { Optimization }\end{array}$ & Min: $M_{t}$ & - & Selection of components & - & - & According to data feasibility \\
\hline \multirow{3}{*}{$\begin{array}{c}\text { Structure } \\
\text { Optimization }\end{array}$} & \multirow{3}{*}{ Min: $M_{s t}$} & $t_{s}$ & Body thickness & $\mathrm{m}$ & \multirow{3}{*}{$\begin{aligned} t_{s m}-2<t_{s}<t_{s m} \\
- \\
-\end{aligned}$} & - \\
\hline & & $J$ & Stiffener rigidity & $\mathrm{m}^{4}$ & & Stiffener selection \\
\hline & & - & Structural Materials & - & & - \\
\hline $\begin{array}{l}\text { Propulsion system } \\
\text { convergence }\end{array}$ & $\beta_{n}-\beta_{n-1}<\varepsilon$ & $\beta$ & Propulsion Mass factor & - & $0.8<\beta<1.5$ & According to statistical data \\
\hline $\begin{array}{l}\text { Stages fuel mass ratio } \\
\text { convergence }\end{array}$ & $\alpha_{n}-\alpha_{n-1}<\varepsilon$ & $\alpha$ & Stages mass factor & - & $0.08<\alpha<0.3$ & According to statistical data \\
\hline
\end{tabular}

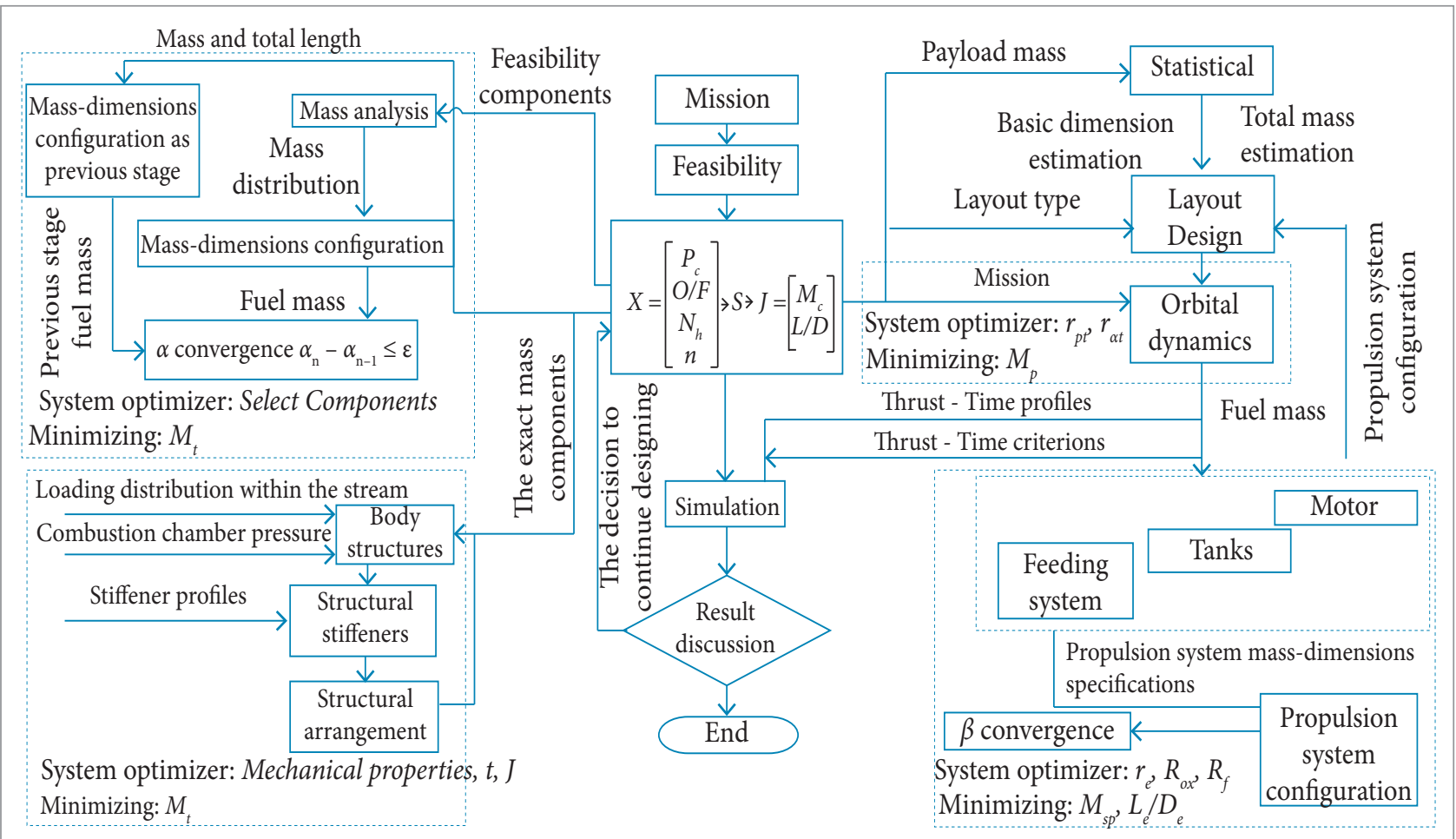

Figure 4. MSDO algorithm. 
However, the most important outputs of the algorithms include the following:

- Multidisciplinary optimization system.

- Adaptation of all design parameters.

- Meeting all the requirements and limitations.

\section{DESIGN METHODOLOGY OF SUBSYSTEMS}

\section{Statistical Design}

Preliminary estimation of systematic parameters in upper stage design process is of utmost importance due to the following reasons: creating a basic configuration for upper stage and faster convergence and more optimal design.

In statistical design via obtained data, the created population and needed graphs were extracted to create initial input (Mirshams and Khaladjzadeh 2010). For instance, 2 sample graphs are given in Figs. 5 and 6. The payload mass is the first and the most important input in designing an upper stage.

$$
M_{k}=1.58+1.2 M_{p a y} \quad\left(R^{2}=0.96\right)
$$

where: $M_{k}$ and $M_{\text {pay }}$ are the final and payload mass.

The thrust to weight relative to burn time is represented by:

$$
\begin{gathered}
n=19.38-0.035 t+2.6 \times 10^{-5} t^{2}-6.88 \times 10^{-9} t^{3} \\
\left(R^{2}=0.98\right)
\end{gathered}
$$

Statistical equations are derived as follows: $\mu_{p}$ and $\mu_{f}$ payload mass ratio and dry mass ratio.

$$
\begin{aligned}
& M_{F}=0.026 M_{\text {pay }}^{2}+0.799 M_{\text {pay }}+2.546 \\
& M_{0}=-0.066 M_{F}^{2}+3.439 M_{F}+3.004 \\
& M_{P}=0.91 M_{0}^{0.917} \\
& \mu_{p}=3.267 \mu_{f}^{2}-0.559 \mu_{F}+0.273 \\
& n=2880 t^{-0.94} \\
& T=3.668 n^{2}-20.21 n+107.7 \\
& \dot{m}=0.525 n^{2}-0.937 n+14.45 \\
& T=4422\left(\dot{m}=\frac{M_{P}}{t}\right)-0.497
\end{aligned}
$$

$$
\begin{aligned}
& L=109.5 e^{-2.33 D} \\
& L D^{2}=0.323 M_{0}^{2}-7.997 M_{0}+116.6
\end{aligned}
$$

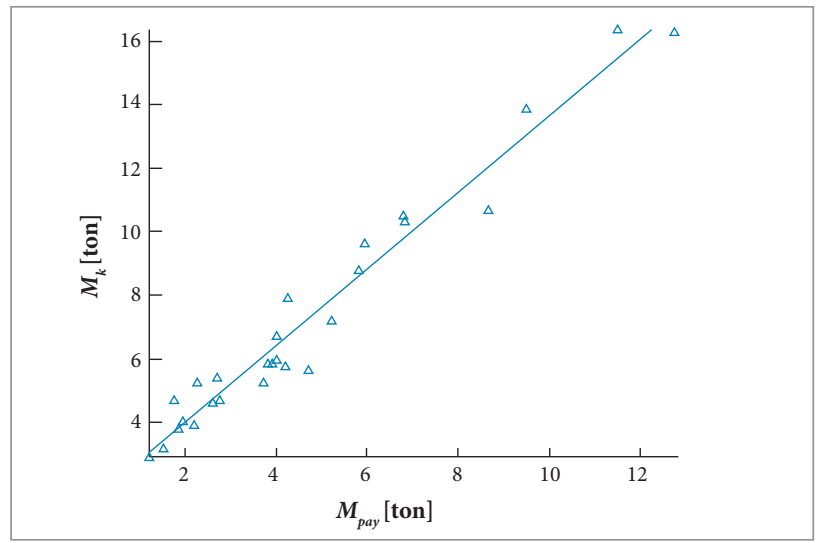

Figure 5. Dry mass versus payload mass.

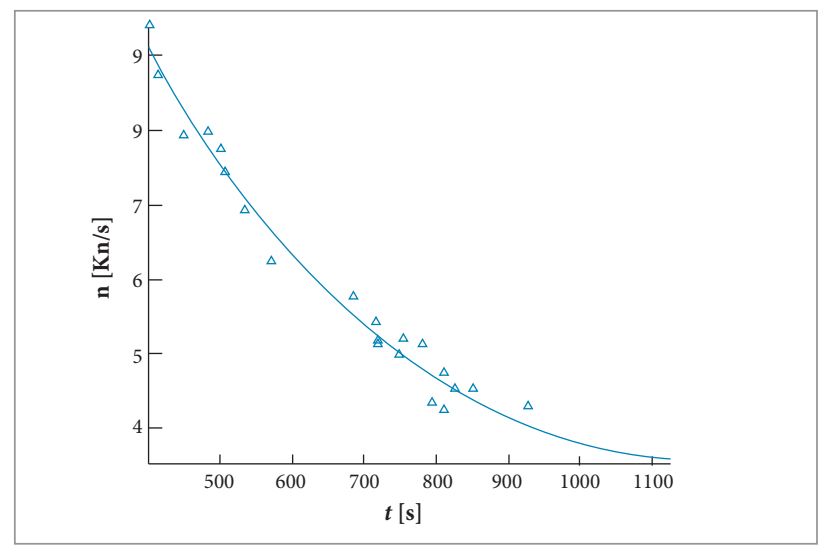

Figure 6. Thrust/weight versus burn time.

\section{Trajectory Simulation and Design}

In this study, trajectory design (Fig. 7) is done based on Hahman's approach as well as 2 references (Chobotv 1996; Curtis 2005).

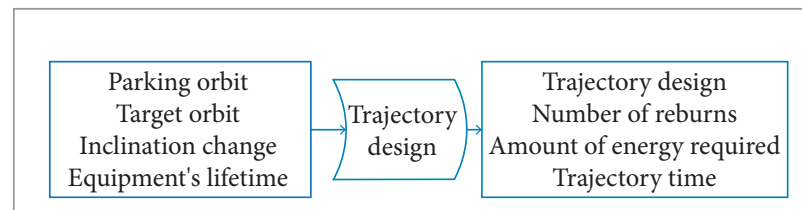

Figure 7. Trajectory design algorithm.

\section{Mass Analysis}

According to statistical studies, linear relationship between the dry mass of the rocket block with the portable 
mass of the same rocket block represents the similarity of mass ranges of the whole subsystems and their subcategories in each block with the same objectives. Thus, determining mass ranges of the main subcategories based on the main effective parameters is viable. In Table 4, all the objects and the way to achieve them are illustrated. Final mass of the upper stage is achieved via the table and considering all the mass parameters. The final mass of upper stage can be achieved with all mass parameters presented in Table 4.

Table 4. Distribution of the mass components.

\begin{tabular}{|c|c|c|c|c|}
\hline \multicolumn{2}{|c|}{ Upper Stage } & Estimated mass & Computational mass & Selective mass \\
\hline \multirow{7}{*}{ Structure } & Satellite installation stand & $x$ & & \\
\hline & Body structure & & $x$ & \\
\hline & Tank protector & $x$ & & \\
\hline & Motor holder & $x$ & & \\
\hline & Nacelle & $x$ & & \\
\hline & Motor front and back flange & & $x$ & \\
\hline & Separation equipment & $x$ & & \\
\hline \multirow{3}{*}{ Feeding system } & Helium & & $\times$ & \\
\hline & Helium tank & & $x$ & \\
\hline & Other equipment & $\times$ & & \\
\hline \multirow{7}{*}{ Propulsion } & Fuel tank & & $x$ & \\
\hline & Oxidant tank & & $x$ & \\
\hline & Connection tunes & $\times$ & & \\
\hline & Motor elements & $x$ & & \\
\hline & Combustion chamber & & $x$ & \\
\hline & Nozzle & & $x$ & \\
\hline & Other components of motor & $\times$ & & \\
\hline \multirow{6}{*}{$\begin{array}{l}\text { Guidance and } \\
\text { control hardware }\end{array}$} & Flight computer & & & $\times$ \\
\hline & Guidance control block & & & $x$ \\
\hline & Inertia measurement block & & & $x$ \\
\hline & Valves & $\times$ & & \\
\hline & Accessories & $x$ & & \\
\hline & Telemetric system & $\times$ & & \\
\hline \multirow{5}{*}{ Actuators } & Electromechanical actuators & & & $\times$ \\
\hline & Cables and electrical connections & $\times$ & & \\
\hline & Thrusters & & & $x$ \\
\hline & Braking motor & & & $\times$ \\
\hline & Acceleration motor & & & $x$ \\
\hline \multirow{3}{*}{ Cases guidance } & Central computer & & & $\times$ \\
\hline & Sensors & & & $\times$ \\
\hline & Gyro planes & & & $x$ \\
\hline
\end{tabular}




\section{Propulsion Subsystem Analysis}

Different specifications of a space propulsion system with other propulsion systems of a rocket are summarized as (Friedman and Kenny 1965):

- Different outside conditions (space conditions).

- On-Off numbers (based on the trajectory design).

- Less thrust-to-weight ratio.

- The use of pressure feed system (high accuracy but low thrust) (Sutton and Biblarz 2001).

Figure 8 shows the propulsion analysis algorithm.

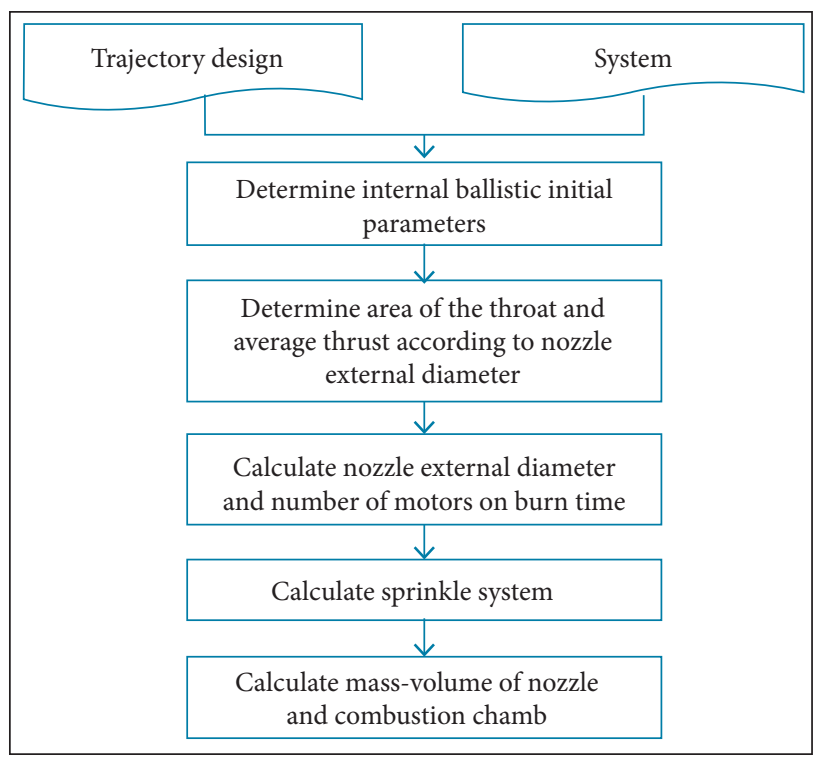

Figure 8. Propulsion sub-algorithm.

\section{Propulsion System Convergence}

In the first design loop, the amount of fuel mass and the final mass of upper stage in every burning is calculated through the following equations:

$$
\begin{aligned}
& \left.M_{f 1}=M_{0} e^{-\left(\Delta V_{1} / I_{\rho p} g_{0}\right.}\right) \\
& M_{P 1}=M_{0}-M_{f 1} \\
& M_{f i}=\left(M_{0}-\sum_{k=1}^{i-1} M_{p k}\right) e^{-\left(\Delta V_{i} / I_{s p} g_{0}\right)} \\
& M_{P i}=M_{0}-\sum_{k=1}^{i-1} M_{p k}-M_{f i} \\
& M_{P}=\sum_{k=1}^{i} M_{P i}
\end{aligned}
$$

After propulsion system design convergence, the amount of optimal fuel mass in every engine-on status is achieved. In the present study, the optimal propulsion system design is achieved through converging the structural convergence factor $(\beta)$. Using upper stage mass in every design loop, all subsystems' propulsion design is achieved and then the new value for fuel mass and convergence factor is obtained.

$$
M_{p j}=\frac{1-\beta}{\beta}\left(M_{s h j}+M_{s e j}+M_{s T j}\right)
$$

where: $j$ is the integration loop counter design; $M_{s h}, M_{s e}$, and $M_{s T}$ are dry mass of subsystems. The equation for convergence coefficient $(\beta)$ is defined as follows:

$$
\beta=\frac{M_{s}}{M_{s}+M_{p}}
$$

The internal relations of the propulsion system are shown in Fig. 1.

\section{Feeding System Analysis}

Controlling pressure in fuel tanks is easily possible using the pressure system feed. Furthermore, the simplicity of adjusting pressure in pressure system feed determines its high reliability, thus the process of switching and flow control is easily possible. Output flow could be controlled with installing a heater or pressure control valves. Generally, the concurrent process of disembarkation of capsules containing compressed gas and filling propellant tanks could be shown via Eqs. 24 and 25 (Huzel et al. 1992).

High-pressure tanks (capsules):

$$
I\left\{\begin{array}{l}
\frac{d p}{d t}=\frac{(k-1) Z}{V}\left(\frac{d Q}{d t}-\dot{m}_{d} h_{d}-\frac{P V}{(k-1) Z^{2}} \frac{d Z}{d t}\right) \\
\frac{d t}{V}=-\frac{\dot{m}_{d}}{V} \\
T=\frac{P}{R \rho}
\end{array}\right.
$$

Propellant tanks:

$$
I I\left\{\begin{array}{l}
\frac{d p}{d t}=\frac{(k-1)}{V(t)}\left(\frac{d Q}{d t}-\dot{m}_{i} h_{i}-\frac{k}{(k-1)} P \frac{d V(t)}{d t}\right) \\
T(t) \\
T=\frac{P}{R \rho}
\end{array}\right.
$$


where: $Q$ is heat transfer between the gas blowing and its environment; $Z$ is the gas compressibility factor; $V$ is the volume control; $T$ is the temperature; $P$ is the pressure; $\dot{m}_{i} \cdot \dot{m}_{d}$ are blowing gas mass flow rate input and output volume control; $h_{i}$ and $h_{d}$ are blowing gas enthalpy entry and exit control volume.

The sub-algorithm of feeding system is shown in Fig. 9.

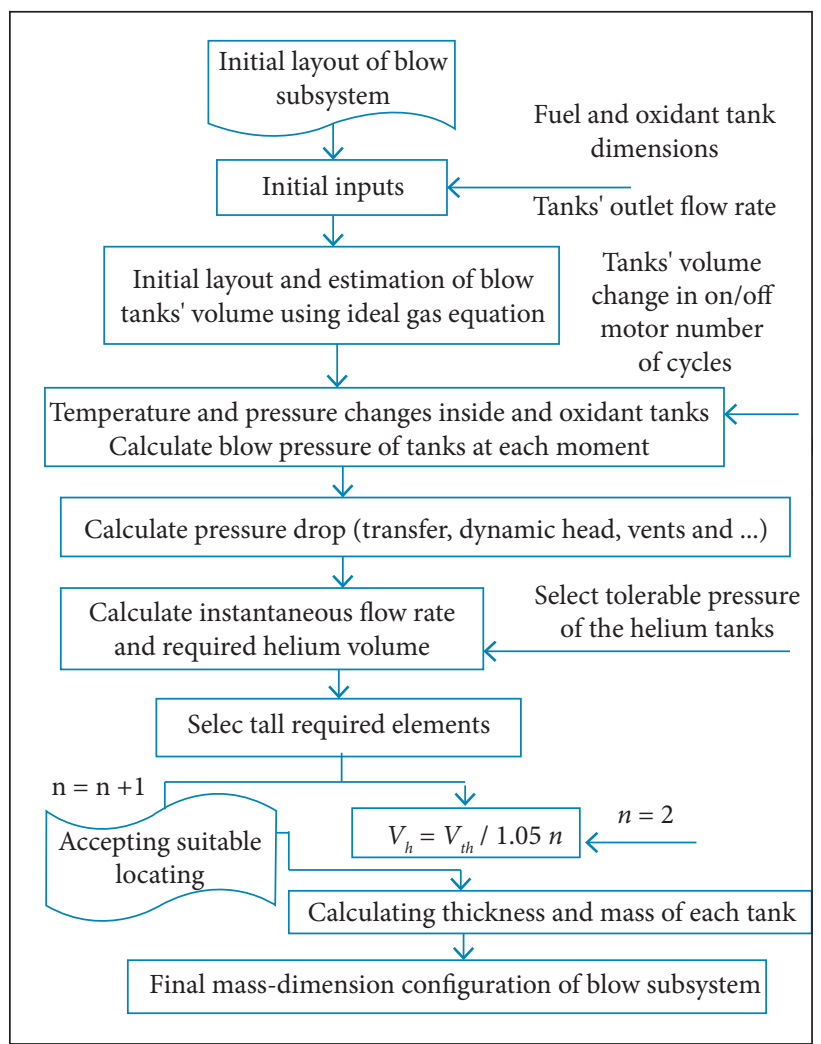

Figure 9. Blow system sub-algorithm.

Volume, thickness, and the mass of every helium tank is obtained from the following equations (Humble et al. 1995):

$$
\begin{aligned}
& V_{h}=\frac{\gamma P_{p o}}{P_{b o o}-P_{b o e}} V_{T o}+\frac{\gamma P_{p f}}{P_{b f o}-P_{b f e}} V_{T f} \\
& t_{G}=\frac{P_{h o}}{2 \sigma_{h w}} R_{h} \\
& M_{T h}=\frac{3}{2} \frac{\rho_{h w}}{\sigma_{h w}} \frac{2 W_{b}}{1-\left(\frac{P_{G e}}{P_{G o}}\right)}
\end{aligned}
$$

where: $\mathrm{V}_{\mathrm{h}}, \mathrm{t}_{\mathrm{G}}$ and $\mathrm{M}_{\mathrm{Th}}$ are volume, thickness, and mass of blowing tanks; $\sigma_{h w}$ and $\rho_{h w}$ are the mechanical properties.
According to blow subsystem sub-algorithm, numbers of blow tanks are selected considering configuration and layout. The final mass of feeding system is calculated by the following equation:

$$
m_{\text {hellium }}=m_{h}+m_{\text {line }}+m_{h e}+m_{\text {valve }}+m_{\text {heater }}
$$

\section{Tanks Analysis}

The shape of the tank is a function of weight, leakage rate, tank volume, and locating restrictions. Spherical tanks have the best empty weight-to-loaded weight ratio (Hutchinson and Olds 2004). Tank design sub-algorithm is shown in Fig. 10. Other elements such as control valves are selected according to input pressure and flow rate.

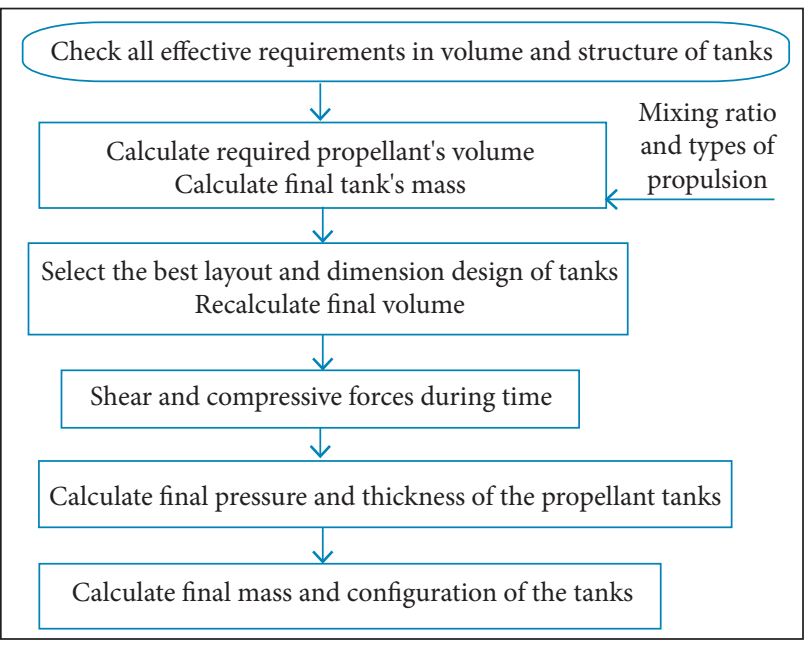

Figure 10. Tank design sub-algorithm.

\section{Structure Analysis}

In structural analysis, providing stability and structural strength to deal with all external pressures is the main goal. In order to determine the mass of the structure, at first, the loads on each section of the structure shall be determined via different stages of preparation to the end of the flight. Loads on each section mean axial force, shear force and bending torque which is applied under external loads during structure mission. Critical load for each section is occurred based on existing experiences in any of the selected above stages. Loading sub-algorithm and the thickness of the body structure is shown in Fig. 11.

After calculating longitudinal and lateral load flow, equivalent stresses are obtained and exerted to the structure which determines the thickness of the body (Ardema et al. 1996; Crawford and Burns 1963). 


$$
\begin{aligned}
& N_{x}=N_{\text {xbend }}+N_{\text {xaxial }}+N_{\text {xullage }}+N_{\text {xhead }} \\
& \sigma_{n}=\frac{1}{\pi D t}\left(N+\frac{4 M}{D}\right) \\
& N_{\text {equ }}(x)=N(x)+\frac{4 M(x)}{D(x)} \\
& t=\frac{N_{\text {equ }}}{\pi D \sigma_{n}}
\end{aligned}
$$

where: $N$ is the axial force; $M$ is the bending moment.

According to the critical situation exerted on the upper stage structure, lateral stiffeners with low number could be used to strengthen body structure. Design algorithm for strengthening stiffeners is shown in Fig. 12.

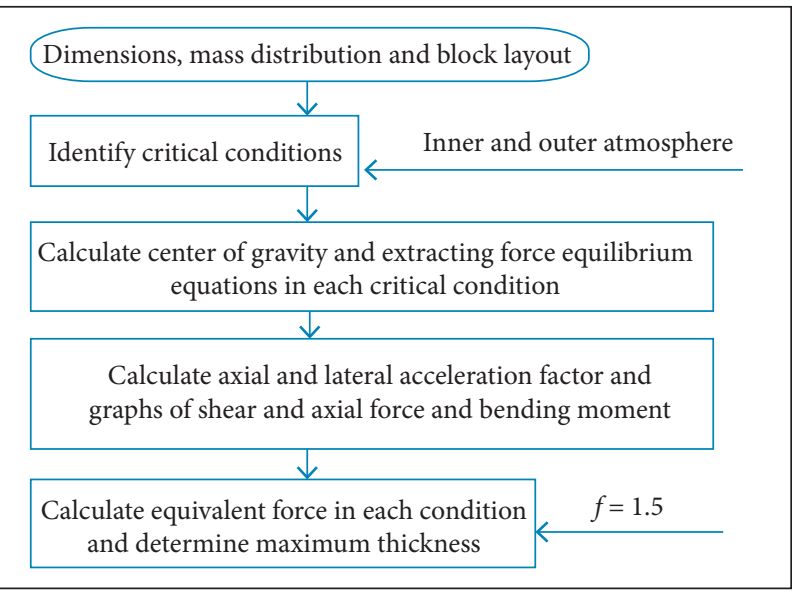

Figure 11. Body structure sub-algorithm.

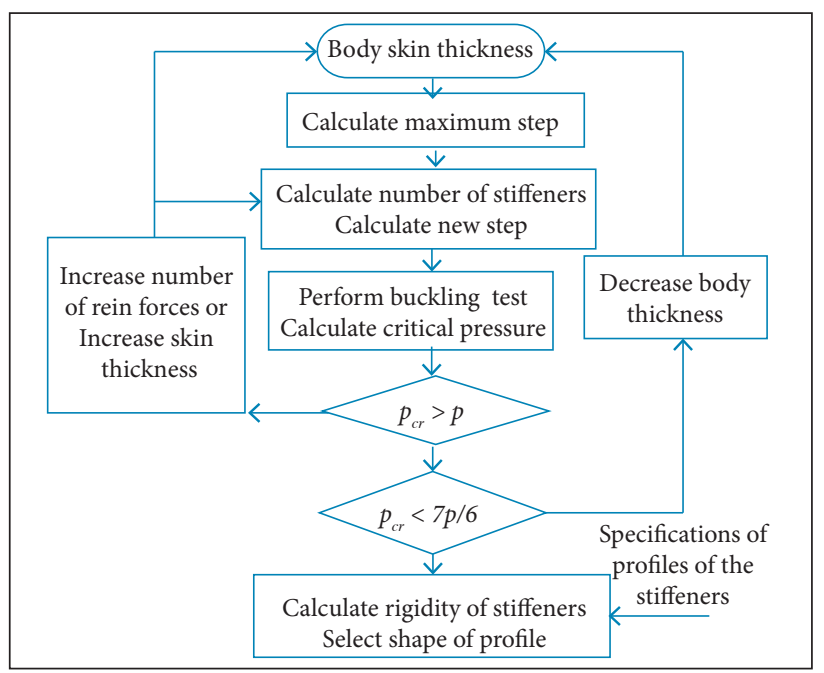

Figure 12. Stiffener structure sub-algorithm.
Stiffener rigidity and then the shape of the stiffener profile can be selected through the following equation:

$$
J=\frac{(N+1)^{4 / 3}-1}{(N+1)} \frac{t^{3}}{12\left(1-\mu^{2}\right)}
$$

where: $J$ is the rigidity stiffener.

\section{Dimension Design}

Dimension design is achieved with 2 different assumptions which, in one, upper stage diameter was determined and, in the other, it was calculated in the output. The calculation of the length and diameter can be achieved through the following equation:

$$
\begin{aligned}
& L_{t}=L_{f}+L_{o}+L_{o f}+L_{e}+L_{s} \\
& D_{t}=D_{p}+2\left(t_{s}+t_{t}+t_{r}\right)
\end{aligned}
$$

\section{RESULTS}

\section{SAMPLE SOLUTION}

A sample solution for upper stage design is presented in this section to generally introduce the design method:

1. Mission definition

- Payload mass is 1.5 tones with parking orbit which is $200 \mathrm{KMs}$ and destination orbit is $36000 \mathrm{KMs}$ with inclination of 45 degrees change.

- Other design inputs are based on requirements and limitations.

2. Results of supplying design initial inputs are shown in Table 5.

Table 5. Initial input.

\begin{tabular}{|c|c|}
\hline Input variable & Values \\
\hline$\beta$ & 0.162 \\
\hline$T(\mathrm{kn})$ & 48.36 \\
\hline$\mu_{p}$ & 0.75 \\
\hline$M_{P}($ ton $)$ & 10.23 \\
\hline$M_{F}$ (ton) & 3.47 \\
\hline$M_{0}$ (ton) & 13.70 \\
\hline
\end{tabular}

3. Trajectory design:

- Hohmann's transfer (3 times Re burn).

- Determining transfer orbit (according to energy limitation and optimized mode). 
4. Determining material and construction inputs of the subsystem:

- Used mechanical properties, environmental conditions, used fluid properties.

- Determining fuel and oxidizer (hydrogen/oxygen).

5. Initial feasibility based on ability to transport about 13 tones to the parking orbit through stages of launcher rocket.

6. System design:

- Determining configuration parameters according to Table 4.

- $\quad$ Selecting initial mass factor.

7. Propulsion design parameters (Table 6).

Table 6. Propulsion engine parameters.

\begin{tabular}{|c|c|c|}
\hline Parameter name & Input variable & Values \\
\hline Thrust factor & $\mathrm{C}_{\mathrm{f}}$ & 1.68 \\
\hline Nozzle expansion ratio & $\mathcal{E}$ & 37 \\
\hline Specific impulse & $I s p$ & 326 \\
\hline Burning time & $t_{b}(\mathrm{~s})$ & 680 \\
\hline Thrust & $T(\mathrm{kn})$ & 60 \\
\hline Propulsion flow rate & $\dot{m}(\mathrm{~kg} / \mathrm{s})$ & 20.52 \\
\hline Motor mass & $m_{m}(\mathrm{~m})$ & 497 \\
\hline Motor diameter & $d_{m}(\mathrm{~m})$ & 0.852 \\
\hline Motor length & $L_{m}(\mathrm{~m})$ & 2.04 \\
\hline Nozzle length & $L_{n}(\mathrm{~m})$ & 1.14 \\
\hline Nozzle outlet diameter & $d_{e}(\mathrm{~m})$ & 0.78 \\
\hline
\end{tabular}

8. Feeding system design (Table 7):

Table 7. Feeding system parameters.

\begin{tabular}{|c|c|c|}
\hline Parameter name & Input variable & Values \\
\hline Blowing system mass & $m_{h}(\mathrm{~kg})$ & 66 \\
\hline Cases blowing mass & $M_{T h}(\mathrm{~kg})$ & 34.5 \\
\hline Helium mass & $m_{h e}(\mathrm{~kg})$ & 20.6 \\
\hline Thickness of helium tanks & $t_{h}(\mathrm{~mm})$ & 4.45 \\
\hline Radius of helium tanks & $r_{h}(\mathrm{~mm})$ & 257 \\
\hline Number of helium tank & $N_{h}$ & 6 \\
\hline
\end{tabular}

a. Selecting pressure-feed system.

b. Calculating pressure drop in fuel flow which is 3.2 bars and for oxidant is 4 bars.

c. Fuel tank pressure 11.2 bars and oxidant 12 bars.
9. Design of tanks: mass and volume of tanks (Table 8).

Table 8. Tank parameters.

\begin{tabular}{|c|c|}
\hline Parameter name & Values \\
\hline Oxidant volume & $7.050 \mathrm{~m}^{2}$ \\
\hline Oxidant mass & $9.669 \mathrm{ton}$ \\
\hline Fuel volume & $4.2827 \mathrm{~m}^{2}$ \\
\hline Fuel mass & $3.581 \mathrm{ton}$ \\
\hline Oxidant tank radius & $1.1895 \mathrm{~m}$ \\
\hline Fuel tank radius & $1.1895 \mathrm{~m}$ \\
\hline Oxidant tank pressure & $12 \mathrm{bar}$ \\
\hline Fuel tank pressure & $11.2 \mathrm{bar}$ \\
\hline Fuel tank thickness & $0.72257 \mathrm{~m}$ \\
\hline Oxidant tank thickness & $3.801 \mathrm{~mm}$ \\
\hline Fuel tank thickness & $3.5485 \mathrm{~mm}$ \\
\hline
\end{tabular}

10. Body structure: determining body thickness and stiffener which requires determining critical modes properties of previous steps, fairing and types of stiffener.

11. Mass distribution:

- Determining mass distribution (Table 9).

- $\quad$ Upper stage primary masses.

Table 9. Other components mass distribution.

\begin{tabular}{|c|c|}
\hline Parameter name & Values $[\mathrm{kg}]$ \\
\hline Control block & 245.88 \\
\hline Actuators & 94.56 \\
\hline Cables & 113.48 \\
\hline Body & 189.1397 \\
\hline Telemetry & 151 \\
\hline Stand & 150 \\
\hline Disposal system & 60 \\
\hline Engine maintenance & 28.28 \\
\hline Control segments & 18.91 \\
\hline Long tube & 31 \\
\hline Flanges & 28.28 \\
\hline Separation & 75 \\
\hline Gyro planes and IMU & 35 \\
\hline
\end{tabular}

12. Upper stage mass and dimensions:

- Upper stage dimensions (Table 10).

- $\quad$ Upper stage primary masses (Table 11). 
Table 10. Diameter and total length.

\begin{tabular}{|c|c|}
\hline Parameter name & Values \\
\hline Dimensional ratio & 2.7812 \\
\hline Diameter $(\mathrm{m})$ & 2.4921 \\
\hline Total length $(\mathrm{m})$ & 6.9314 \\
\hline
\end{tabular}

Table 11. Mass parameters.

\begin{tabular}{|c|c|}
\hline Parameter name & Values \\
\hline Fuel mass & 13.249 \\
\hline Final mass & 3.391 \\
\hline Structure mass & 1.891 \\
\hline Total mass & 16.64 \\
\hline
\end{tabular}

\section{DIFFERENT VARIANTS AND VALIDATION}

Technology for constructing a launch vehicle in countries varies from each other, however, the statistical graphs indicate the approximate similarity of systematic parameters for upper-stage systems. For instance, Fig. 13 shows the relationship of payload mass and dry mass in the upperstage system. The real samples are circular and the samples derived from this paper for UDMH/N204 fuel are squareshaped. The comparative curve of burn time due to thrust/ weight is presented in Fig. 14. Convergence factors ( $\alpha$ and $\beta)$ are illustrated in Figs. 15 and 16.

The close similarity of these graphs is the main reason to validate the results derived from the study. At this point another validation was compared with Cent.D-5 upper-stage of Atlas V (401) which is presented in Table 12. Problem inputs: $M_{\text {pay }}=4.75$ ton; $\mathrm{D}=3.05 \mathrm{~m}$ and $\mathrm{I}_{\mathrm{sp}}=4378 \mathrm{~N}^{*} \mathrm{~s} / \mathrm{kg}$.

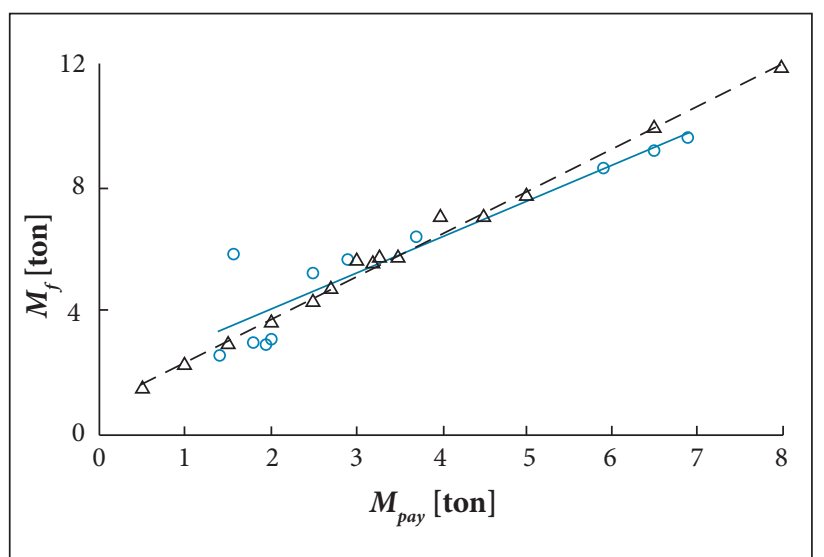

Figure 13. Final mass versus payload mass.
In Table 13, the errors in the statistical design methods and MSDO compared to the systematic data of Cent. D-5 upper stage system. As shown in Table 5, errors of fuel mass, dry mass and total mass in MSDO design are decreased by 9 to $16 \%$ compared with Cent. D-5. Furthermore, the accuracy of primary data derived from the statistical design is obvious in this table.

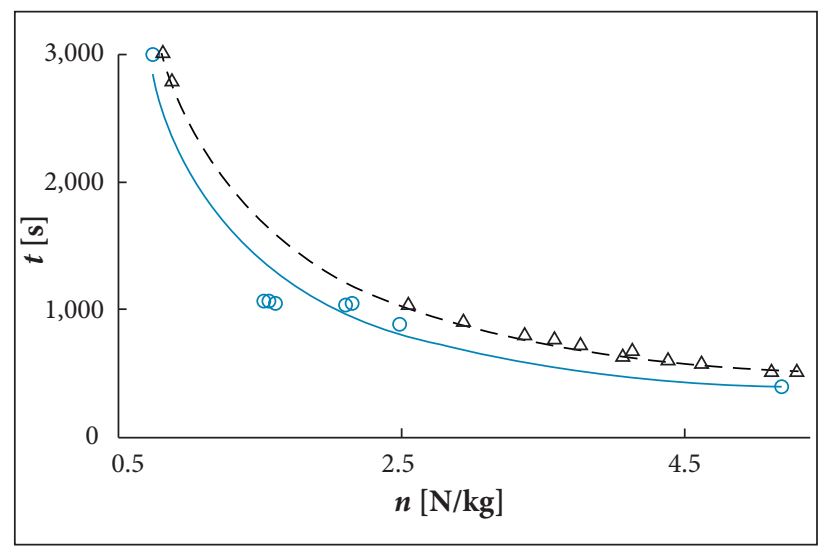

Figure 14. Comparative curve of burn time due to $T / W$.

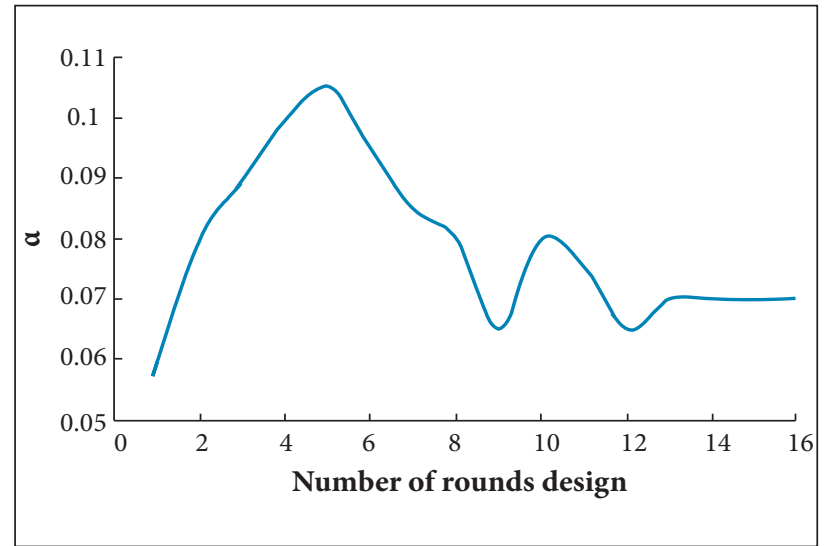

Figure 15. Convergence factor $\alpha$.

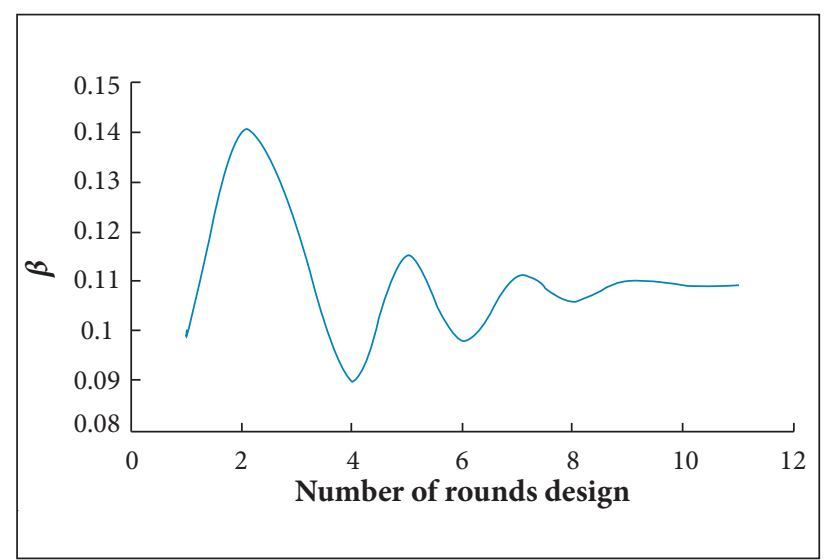

Figure 16. Convergence factor $\beta$. 
Table 12.Comparation of validation to Cent D-5 upper-stage.

\begin{tabular}{|c|c|c|c|c|c|c|}
\hline Output data & $M p$ (ton) & $M_{O}$ (ton) & $\mu_{f}$ & $\mu_{p}$ & $\beta$ & $n(\mathbb{N} / \mathrm{kg})$ \\
\hline System parameters Cent. D-5 & 19.65 & 26.78 & 0.266 & 0.18 & 0.10 & 3.64 \\
Statistical design & 16.8 & 23.66 & 0.29 & 0.2 & 0.11 & 3.88 \\
MSDO & 18.93 & 26.01 & 0.27 & 0.182 & 0.109 & 3.61 \\
\hline
\end{tabular}

Table 13. Methods errors compared to the systematic data of Cent. D-5 upper stage system

\begin{tabular}{c|c|c|c|}
$\begin{array}{c}\text { Design type } \\
\text { method }\end{array}$ & $\begin{array}{c}\text { Propellant } \\
\text { weight [\%] }\end{array}$ & $\begin{array}{c}\text { Dry weight } \\
{[\%]}\end{array}$ & $\begin{array}{c}\text { Lift off } \\
\text { weight [\%] }\end{array}$ \\
\hline Statistical & 11.6 & 11.3 & 14.5 \\
MSDO & 0.2 & 2.1 & 3.66 \\
0.27 & 0.182 & 0.109 & 3.61 \\
\hline
\end{tabular}

\section{CONCLUSION}

Design processes of all elements are done simultaneously in this paper. In each design loop, calculations become more accurate and results of each section, more suitable according to other systems. In this design method, a mistake can be found by system (because it affects all elements) and it would be easier to fix it. The main results are:

- Proportional with technology and ability for construction.

- Logical relation of all segments and subsystems.

- Developing a national design and method.
- Presenting a sample upper stage according to different inputs.

- Logical convergence of parameters to logical values.

- Ability of performing general feasibility.

- Extensibility to accurate initial design.

- Ability of networking the design under supervision of the system.

- Designing systematic sample of upper stage.

- General guideline based on implementation of detail design (limitations of methods and range of parameters).

- All the important design points are specified in order to divide the algorithm for performing different projects.

\section{AUTHOR'S CONTRIBUTION}

Zakeri M has provided the article's text; Nosratollahi M and Novinzade A carried out the guidance and control of the paper; the final set was conducted by Zakeri M and Nosratollahi M; the idea was developed by all authors.

\section{REFERENCES}

Adami A, Mortazavi M, Nosratollahi M (2015) A new approach in multidisciplinary design optimization of upper-stages using combined framework. J Acta Astronautica 114:174-183. doi: 10.1016/ j.actaastro.2015.04.011

Aldheeb MA, Kafafy R, Idres M, Omar HM, Abido MA (2012) Design optimization of micro air launch vehicle using differential evolution. J Aerosp Technol Manag 4(2):185-196. doi: 10.5028/ jatm.2012.04020112

Balesdent M, Bérend N, Dépincé P, Chriette A [2011) A survey of multidisciplinary design optimization. Structural and Multidisciplinary Optimization 45(5):619-642. doi: 10.1007/s00158-011-0701-4

Brown NF, Olds JR (2006) Evaluation of multidisciplinary optimization techniques applied to a reusable launch vehicle. J Spacecraft Rockets 43(6): 1289-1300. doi: 10.2514/1.16577

Casalino L, Pastrone D (2010) Optimal design of hybrid rocket motors for launchers upper stages. J Propul Power 26(3):421-427. doi: $10.2514 / 1.41856$

Chambers MC, Ardema MD, Patron AP, Hahn AS, Miura H, Moore $\mathrm{MD}$ (1996) Analytical fuselage and wing weight estimation of transport aircraft. NASA TM-110392.

Chobotv VA (1996) Orbital mechanics. Reston: American Institute of Aeronautics and Astronautics.

Crawford RF, Burns AB (1963) Minimum weight potentials for stiffened plates and shells. AIAA J 1(4):879-886. doi: 10.2514/3.1658

Curtis HD (2005) Orbital mechanics for engineering students. Oxford: Elsevier Butterworth-Heinemann.

Diedrich A, Hileman J, Tan D, Willcox K, Spakovszky Z (2006) Multidisciplinary design and optimization of the silent aircraft. Proceedings of the 44th AIAA Aerospace Sciences Meeting and 
Exhibit; Reno, USA.

Fleeman EL (2001) Technologies for future precision strike missile systems - missile design technology. Paper presented at: RTO SCl Lecture Series on Technologies for Future Precision Strike Missile Systems. Published in RTO-EN-018; Madrid, Spain.

Friedman PA, Kenny RJ (1965) Chemical pressurization of hypergolic liquid propellants. J Spacecraft Rockets 2(5):746-753. doi: $10.2514 / 3.28273$

Humble RW, Henry GN, Larson WJ (1995) Space propulsion analysis and design. New York: McGraw-Hill.

Hutchinson VL, Olds JR (2004) Estimation of launch vehicle propellant tank structural weight using simplified beam approximation. Proceedings of the 4Oth AIAA/ASME/SAE/ASEE Joint Propulsion Conference and Exhibit; Florida, USA.

Huzel DK, Huang DH, Arbit H (1992) Modern engineering for design of liquid-propellant rocket engines. Washington: American Institute of Aeronautics and Astronautics.

Mirshams M, Khaladjzadeh L (2010) Drivation of system level characteristics of a manned spacecraft by applying statistics models. Journal of Space Science and Technology 3(1-2):25-36. In Persian.

Motlagh JA, Novinzadeh AB, Zakeri M (2013) New approach in designing solid upper stage for interplanetary missions using finite burn assumption. IEEE Aero Electron Syst Mag 28(10):36-43. doi:

\subsection{9/MAES.2013.6642830}

Olds JR (1993) Multidisciplinary design techniques applied to conceptual aerospace vehicle design ( $\mathrm{PhD}$ thesis). Raleigh: North Carolina State University.

Peoples R, Schuman T (2003) A joint performance and financial approach to aircraft design optimization; [accessed 2016 Sept 27]. https://dspace. mit.edu/bitstream/handle/1721.1/68163/16888-spring-2004/contents/projects/6peoples_schuman.pdf

Riddle E (1998) Use of optimization methods in small satellite systems analysis. Paper presented at: 12th AIAA/USU Conference on Small Satellites; Logan, USA.

Sutton GP, Biblarz O (2001) Rocket propulsion elements. Lewiston: John Wiley \& Sons.

Tsuchiya T, Mori T (2002) Multidisciplinary design optimization to future space transportation vehicles. AIAA-2002-5171.

Villanueva FM, Linshu $H$, Dajun X (2013) Kick solid rocket motor multidisciplinary design optimization using genetic algorithm. J Aerosp Technol Manag 5(3):293-304. doi: 10.5028/JATM.v5i3.225

Wronski J, Gray JM (2004) Multi-disciplinary system design optimization of the F-350 rear suspension; [accessed 2016 Sept 27]. http://core.csu.edu.cn/NR/rdonlyres/Aeronautics-andAstronautics/16-8885pring-2004/CAC1955D-2E22-4307-A7A8905105DD9900/0/wronski_gray.pdf 